\title{
TRANSPLANTE DE MEDULA ÓSSEA: UMA CONFLUÊNCIA BIOPSICOSSOCIAL'
}

\section{BONE MARROW TRANSPLANT: A BIOLOGICAL AND PSYCHOSOCIAL CONVERGENCE}

\author{
Maribel Pelaez Dóro ${ }^{2}$ \\ Ricardo Pasquini ${ }^{3}$
}

\begin{abstract}
RESUMO
O objetivo deste artigo é verificar alguns componentes da contextualização do transplante de medula óssea e a sua interferência nos cuidados e na interpretação da psique-corpo daquele que perpassa pelo adoecimento. A identificação dos aspectos psicológicos do câncer, do transplante de medula óssea, dos pacientes e da morbidade psicossocial é um passo importante em direção aos planos de intervenções terapêuticas. Psicólogos e médicos podem trabalhar juntos com o intuito de reduzir o estresse e contribuir positivamente na recuperação dos pacientes, pois a vivência do transplante de medula óssea inclui a experimentação de alterações físicas, fisiológicas, mobilizações emocionais, funcionais, sociais, familiares e espirituais.
\end{abstract}

Palavras-chave: Transplante de Medula Óssea x Confluência biopsicossocial.

\begin{abstract}
The purpose of this article is to verify certain components of the contextualization of bone marrow transplanting and its interference in the care and interpretation of the psyche-body of the person who is suffering the illnes. The identification of the psychological aspects of cancer, bone marrow transplant, patients and psychosocial morbidity is an important step towards therapeutic intervention plans. Psychologists and doctors can work together with the aim of reducing stress and contributing positively towards patients' recovery, since the experience of a bone marrow transplant includes undergoing physical and physiological alterations, emotional, functional, social, family and spiritual changes.
\end{abstract}

Key words: Bone Marrow Transplant vs. Biological and Psychosocial Convergence.

\section{INTRODUÇÃO}

Em plena era do clone, da engenharia genética e da chegada do novo milênio, ainda nos deparamos com questões básicas na carcinogênese, tais como a especificação da categoria nosológica do câncer (CA), pois esta ainda é genérica e inclui uma diversidade de pressupostos etiológicos, de natureza genética, ambiental e imunológica. No caso da leucemia, especificamente, o acúmulo de resultados favoráveis se dá pela interação de variáveis divergentes, tais como: poliquimioterapia, redução da toxidade e dos agravantes infecciosos ou hemorrágicos. Assim, a intervenção clínica do transplante, por vezes, é a única possibilidade de salvação para o paciente.

A ciência moderna demanda uma busca nas investigações, nas definições e nas possibilidades de objetivar e clarificar as variáveis interferentes no $\mathrm{CA}$, incluindo o indivíduo que adoece, seu contexto sociocultural, pessoal, funcional, emocional; ou seja, alguns dos aspectos envolventes do intra e interpsíquico. Enfim, pesquisadores têm publicado resultados que enfatizam a necessidade de considerar fatores que suplantem a organicidade. Esta preocupação científica promoveu uma alteração no planejamento da formação da equipe que atua diretamente no indivíduo adoecido e na família que o acompanha.

\footnotetext{
${ }^{1}$ Estudo realizado no Hospital de Clínicas, Curitiba, PR - Serviço de Psicologia do HCPR; Serviço de Hematologia e de Transplante de Medula Ossea do HC-PR.

2 Psicóloga responsável pelo Serviço de Transplante de Medula Óssea: Mestre em Psicologia da Infância e da Adolescência pela UFPR.

${ }^{3}$ Chefe responsável pelo Serviço de Transplante de Medula Óssea; Professor Titular da UFPR.
} 
Deste modo, tem-se a percepção de que cuidar da saúde significa ocupar-se com o bemestar global do indivíduo, isto é, de não se restringir ao aspecto biológico. As investigações conduzem a prática clínica para os fenômenos contribuintes da qualidade de vida, não somente daqueles que adoecem mas também dos sobreviventes desta experiência que, por vezes, conduz à morte (Deitos \& Gaspary, 1997; Keogh et al., 1998).

Mundialmente, há uma confirmação da doença maligna dos glóbulos brancos (leucemias), que excede a 120 mil casos por ano. Este número significativo de pacientes e sobreviventes causa um déficit econômico no orçamento particular, institucional e/ou governamental. Porém, também mobiliza os estudiosos para o desenvolvimento e a qualificação do atendimento, uma vez que aquele que tem uma enfermidade vivencia uma situação estressante que pode esvair suas reservas psíquicas, desvinculá-lo das suas relações pessoais e ainda torná-lo vulnerável à perda de seu emprego. Conseqüentemente, estas percepções conduzem a atenção e o incentivo para a compreensão e exploração dos fatores desgastantes que permeiam os tratamentos dos indivíduos que têm um diagnóstico de neoplasia. Assim, é fundamental tecer uma reflexão sobre os elementos que possam interferir na qualidade de vida (QV) daqueles que adoecem e vivenciam a intervenção do transplante de medula óssea, (TMO).

Um dos motivadores principais de causas de mortalidade é o câncer, e para muitas pessoas esta é uma das doenças que mais desencadeia o medo. De fato, a população associa o câncer à desfiguração, à perda da função corporal, emocional, alteração de humor com muita angústia, crises financeiras, intensa dor e morte. Isto se acentua quando o diagnóstico tem um prognóstico ruim, como por exemplo na leucemia linfóide aguda (Bonamin, 1995; Spiegel, 1996; Deitos \& Gaspary, 1997 e Munstedt et al.,1997).

Os achados epidemiológicos que enfocam a etiologia do câncer subdividem-se em três grupos: aspectos genéticos, ambientais e psicossociais. Palmeira (1997) enfatiza o terceiro item, que abrange componentes dos hábitos pessoais, funcionais, emocionais e sociais.

Supõe-se que as tensões psicológicas e os conflitos afetivos possam resultar patologia orgânica e que o contrário, isto é, uma filosofia de vida mais positiva é um fator que pode contribuir na recuperação e na manutenção da saúde.

McQuellon et al. (1998) observaram que pacientes com um ano de transplante apresentavam três tendências para qualidade de vida global: a tendência foi linear e posteriormente melhorou; foi linear e na seqüência piorou; foi ruim e a posteriori melhorou.

Com estas informações demonstrativas da trajetória de recuperação, é possível detectar o movimento de resgate de uma nova construção de saúde e, assim, intervir no pré e póstransplante, auxiliando o paciente para o processo que o espera.

Em 1997, a União Internacional Contra o Câncer (UICC) tentou mobilizar movimentos de pesquisa sobre o CA, nos países de maior precariedade. Enquanto isto, no Brasil, por meio do Instituto Nacional de Câncer (Inca), constata-se que a dificuldade primária para pôr em prática pesquisas fidedignas se estabelece na base da execução científica; isto é, há falta de projetos institucionais com intenções de médio e longo prazo. Neste contexto em que os estudos prolongados estão reduzidos, é difícil manter as informações para, a posteriori, fazer-se a implantação de intervenções terapêuticas que possam promover melhoria da qualidade no acompanhamento e na diretriz das orientações pertinentes ao contexto da população oncológica assistida.

Entretanto, para obter uma análise da realidade resultante das variáveis interferentes na qualidade de vida, primeiramente é fundamental clarificar a definição de qualidade de vida, revisá-la na literatura e na prática clínica para, na seqüência, corroborá-la com atitudes de melhorias na ciência e no conhecimento na psico-oncologia nacional. 


\section{BASES HISTÓRICAS DO ESTUDO SOBRE}

\section{QUALIDADE DE VIDA}

Em 1964, o presidente dos Estados Unidos, Lyndon Johnson, usou o termo qualidade de vida pela primeira vez, ao declarar que: "os objetivos não podem ser medidos pelo balanço dos bancos. Eles só podem ser medidos através da qualidade de vida que proporcionam às pessoas" (Fleck, 1998). Gradativamente, os cientistas sociais, filósofos e políticos passaram a prestar atenção aos aspectos qualitativos dos padrões de vida. Simultaneamente, o desenvolvimento científico e tecnológico da medicina acelerou os avanços nas intervenções, gerando um apanhado de conseqüências indignas de serem vividas. Deste modo, "a qualidade de vida refere-se a um movimento dentro das ciências humanas e biológicas no sentido de valorizar parâmetros mais amplos que o controle de sintomas, a diminuição da mortalidade ou o aumento da expectativa de vida" (Fleck, 1998).

Nesta última década, houve uma explosão de interesse sobre qualidade de vida dos pacientes com câncer.

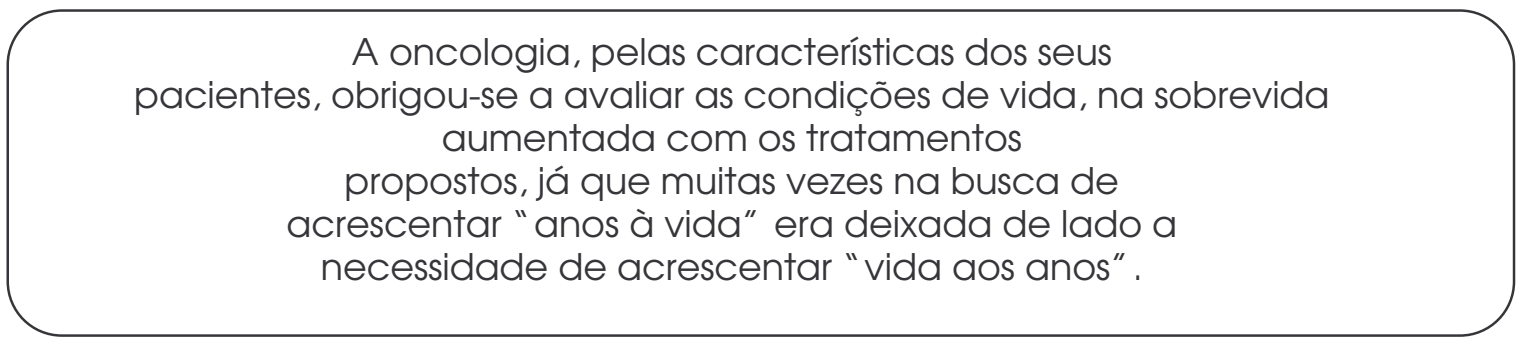

Considera-se a qualidade de vida quando o interesse é voltado para a escolha do melhor tratamento possível. Dentre estes, há os que resultam apenas numa diferença mínima de sobrevida, mas com diferenças significativas nos efeitos colaterais ou no impacto nas funções sexuais e psicossociais. A outra possibilidade de escolha enquadra-se nos novos tratamentos que promovem um avanço significativo de sobreviventes, à custa de alta toxidade (Neitzert et al., 1998).

Enfim, "a avaliação de qualidade de vida foi acrescentada nos ensaios clínicos randomizados como a terceira dimensão a ser avaliada, além da eficácia (modificação da doença pelo efeito da droga) e da segurança (reação adversa às drogas)". Assim, nos últimos anos, o conceito de qualidade com conseqüências saudáveis vem sendo incluído nos argumentos de avaliação para o bem-estar físico e psicológico, de modo que o plano de atendimento médico é avaliado e indicado conforme a importância dada aos seus benefícios e/ou efeitos colaterais.

Nos anos 70 , os profissionais da saúde voltaram-se aos aspectos mensuráveis da qualidade de vida dos pacientes. Esta atenção deu viabilidade a algumas associações para investirem na qualificação do atendimento ao paciente.

$\mathrm{Na}$ oncologia, esta avaliação centrou-se na escolha de tratamentos, manejo da dor e conseqüências médicas. Após o diagnóstico, o procedimento incluía o cuidado com a interação do staff, comunicação sobre tratamentos alternativos, conforto com compaixão e competência da equipe. Enfim, buscava-se um atendimento que possibilitasse a dignidade do paciente, independentemente do estágio processual da doença.

Nos anos 80, foram tomadas medidas para avaliar a percepção dos pacientes em relação a outros aspectos além do orgânico e também para verificar a qualidade dos serviços hospitalares e dos alimentos ofertados nas instituições de saúde.

Nos anos 90, a avaliação da qualidade de vida foi usada de forma mais globalizante, uma vez que objetivava a conferência da melhoria na qualidade dos serviços clínicos, incluindo todos os profissionais de saúde.

A explosão deste interesse na qualidade dos atendimentos e na satisfação do paciente decorreu, em primeiro lugar, da necessidade de controlar e avaliar o custo/benefício; em segundo plano, para melhorar o padrão do atendimento pelo benefício ofertado ao paciente em si. 
Assim, avaliar a qualidade do serviço dos profissionais, da saúde e/ou da vida não é uma tarefa fácil, pois depende-se do referencial em questão, quer seja a estrutura, o processo, as expectativas de resultado e da experiência (Rowland, 1997).

A alta competitividade na área de saúde mobilizou nas organizações envolvidas a utilização da satisfação do paciente como medida hospitalar. Deste modo, medidas de satisfação foram usadas como instrumentos para escolha de planos de saúde e, conseqüentemente, para serviços específicos. Apesar de seu início ter se estabelecido em bases econômicas, hoje o paciente pode usufruir de um atendimento que visa o seu bem-estar geral. A sua subjetividade está menos fragmentada, a dicotomia ficou para demarcar a história dos nossos antepassados; a preocupação e a ocupação voltaram-se para intervenções que amenizem ou propiciem uma qualidade de vida para aquele que a esteja perdendo no processo de enfermidade.

Segundo a Organização Mundial de Saúde (OMS), a definição de qualidade de vida é "a percepção do indivíduo de sua posição na vida no contexto da cultura e sistemas de valores nos quais ele vive e em relação aos seus objetivos, expectativas, padrões e preocupações" (Rowland, 1997; Fleck, 1998).

Com efeito, qualidade de vida é uma construção multifacetada; assim, o número de componentes existentes numa concepção é largamente mostrado nas pesquisas. Entretanto, há um consenso universal, em relação aos fatores mais apresentados, os quais são: multidimensionalidade, subjetividade, presença de valorações positivas (por exemplo: capacidade de execução de tarefas) e negativas - dor e fadiga (Rowland, 1997).

As pesquisas variam, e algumas comparam qualidade de vida em grupos com câncer e normais, ou incluem-se nas pesquisas tipos generalizados de câncer, mas, também estudam-se tipos específicos de câncer. Enfim, com o interesse sobre qualidade de vida das autoridades em saúde, denota-se que está havendo uma mudança de atitude, uma vez que, no início, o sucesso estava centralizado na obtenção de um número de sobreviventes significativos. Atualmente isto é insuficiente, deseja-se alcançar sobreviventes, mas, com mais qualidade de vida. Em relação a este indicativo, pesquisadores, em geral, concordam entre si quanto ao impacto psicossocial e aos efeitos colaterais aflitivos decorrentes da quimioterapia (Padilla, 1983; Neitzert, 1998).

\section{HISTÓRICO DO TRANSPLANTE DE MEDULA ÓSSEA (TMO)}

A base científica da intervenção do TMO surgiu dos estudos com ratos e posteriormente com cães. Kuss \& Bourget (1992) relatam que em 1949, Jacobson e colaboradores demonstraram que camundongos expostos a doses letais de irradiação corporal total poderiam ser resgatados caso o baço fosse protegido, evitando-se a morte por falência medular. Logo depois, em 1951, Lorenz et al. (1952, apud Trevealen \& Barrett, 1992) demonstraram que esta mesma proteção contra a irradiação poderia ser obtida com a infusão de medula óssea. As primeiras tentativas de se utilizar a infusão de células sangüíneas da medula óssea para tratamento em humanos ocorreu em 1957, quando o Dr. Donnall Thomas usou este procedimento em pacientes com leucemia aguda após uma dose considerada letal de irradiação corporal total (400 a 600 rads) (Kuss \& Bourget, 1992; Donnall, Forman \& Blume, 1994).

Inicialmente, as experiências tinham o intuito de testar o sistema e estabelecer os primeiros princípios; isto é, as intervenções continham características de rastreamento, quando os pacientes com câncer demandavam buscas científicas para detectar tratamentos com resultados mais satisfatórios e com menos restrições ao funcionamento físico. Assim, entre as propostas intervencionistas, destaca-se o TMO, procedimento de-senvolvido para tratamentos de doenças hematológicas malignas, não-malignas e alguns casos de tumores sólidos. Freqüentemente, as neoplasias mais indicadas são: leucemia mielóide crônica (LMC), síndrome pré-leucêmica, mielodisplasia, neuroblastoma, gliomas.

As doenças hematopoiéticas não-neoplásicas que podem ter indicação para o TMO são: Anemia aplásica, Anemia de Fanconi, Anemia falciforme, Anemia hipoplásica congênita etc. (Donnall \& Forman, 1994); Whedon \& Wujcik, 1997). 
Esta intervenção clínica difere conforme a procedência da medula óssea. Assim, no TMO alogênico, a fonte da medula óssea é de um doador não aparentado ou aparentado e compatível. Neste caso, pode manifestar a Doença do Enxerto Contra o Hospedeiro (DECH), enfermidade que recebe termos diferenciados, conforme o sítio orgânico em que ataca, por exemplo: DECH de fígado, DECH de pele, DECH de intestino etc.

O procedimento nomeado de TMO autólogo ocorre quando a medula óssea é retirada do próprio paciente; isto é, estimula-se a produção de células progenitoras, retiram-se e são congeladas. Sendo a medula do próprio paciente, evitam-se os riscos de rejeição, ou seja, da $\mathrm{DECH}$. Nos casos em que o paciente e o doador são gêmeos idênticos (univitelinos), denominase TMO singênico. Ao retirar o sangue do cordão umbilical, leva o nome que sugere a própria fonte de extração. Em número ínfimo tem-se pesquisado intervenções clínicas para transplantes de medula óssea, com animais de espécies diferentes; o qual chama-se Xenogênico (Donnall \& Forman, 1994).

Para realizar a infusão das células sangüíneas da medula, do sangue periférico ou do sangue do cordão umbilical, faz-se uma imunossupressão e esta produz um resultado que é o desenvolvimento de um "universo imunológico" diferente. Por isto, no início, acreditou-se que a consigna deveria ser "quanto mais, melhor", isto em relação à quimioterapia, que tem a função de erradicar o tumor. Evidentemente que os outros órgãos eram e são comprometidos. A mortalidade inicial era extrema, devido à toxidade, à grande incidência de infecções e seqüelas tardias.

As causas de morte nos TMO alogênicos são: recaída da doença primária, o DECH é responsável por mais de $15 \%$ de mortalidade, além de predispor a infecções, entre outras o citomegalovírus (CMV). As infecções por fungos são responsáveis por mais ou menos 15 a 20\% da toxidade dos órgãos.

Na América Latina, o Brasil foi o pioneiro país a fazer TMO; tendo como local escolhido para tão ousada responsabilidade o Hospital de Clínicas de Curitiba-PR, constituiu-se então o Serviço de Transplante de Medula Óssea (STMO). Assim, em 1979, realizou-se o primeiro TMO, com um paciente portador de Anemia Aplásica, tendo ele sobrevivido apenas até o sétimo dia após o procedimento. No entanto, ainda hoje se sabe de um ex-paciente que foi transplantado em 1982 e que se encontra com rotina de vida normal.

Em 1989, aconteceu em Paris o primeiro transplante utilizando células sangüíneas de cordão umbilical, em uma criança com Anemia de Fanconi. Esta é uma área que está em crescimento, pois se descobriu que o cordão umbilical é rico em células mães (células totipotenciais), por isto capaz de regenerar a medula óssea. Além disso, a incidência de DECH é menor neste tipo de transplante. No Hospital de Clínicas de Curitiba-PR, realizou-se o primeiro transplante de células sanguíneas de cordão umbilical, aparentado em 1993, com um paciente portador de LMC. Em 1994, foi feito o primeiro transplante de células sangüíneas de cordão umbilical não aparentado.

No ano de 1998, completaram-se mil TMO, no STMO do Hospital de Clínicas de Curitiba - PR,

sendo que, destes, os registros confirmaram

aproximadamente $60 \%$ de sobreviventes, que

acertaram ao depositar neste procedimento a sua última e única solução

praticável.

No ano de 1999, beirando o término do milênio, este STMO completou vinte anos, desde o seu primeiro transplante. $O$ trabalho pertence a uma instituição pública e enfrenta as dificuldades inerentes a tal entidade. Conseqüentemente, possui uma fila de espera para a realização do transplante, em torno de 130 pacientes. Além de atender o Paraná, recebe pacientes de todo o Brasil e da América Latina. Calculando a grosso modo, diante de trinta dias de hospitalização, 
em média, para cada atendimento, subentende-se que a espera possa estender-se de dois anos e meio a três anos, para os pacientes que têm o diagnóstico de LMC. Trata-se de um fator negativo na conservação de um bom prognóstico, uma vez que 50 a $60 \%$ tem sido a projeção para pacientes tratados durante a "primeira remissão" de leucemia. Com esta sobrecarga de candidatos ao transplante, ao internar-se, muitas vezes o paciente se encontra na "segunda ou terceira remissão", degradando o percentual de sucesso. No entanto, este serviço não tem condições de absorver toda a demanda, mesmo porque também precisa dar prioridade aos pacientes com diagnóstico de Anemia Aplásica e de Anemia de Fanconi, por apresentarem uma condição patológica que não permite espera. A recaída e a sobrevida a longo prazo para os transplantados variam conforme o tipo da doença e a sua maior ou menor comorbidade. Nos casos da anemia, o índice hemorrágico é elevado, ocasionando com freqüência a morte ou uma qualidade de vida que o impede de manter sua condição física em padrão viável de produtividade, seja qual for.

\section{INTERFACES BIOPSÍQUICAS}

Parafraseando Shakespeare, não existe o bom e o ruim, a existência qualitativa está nos pensamentos interpretativos. Assim, antes de falar das mudanças que acontecem ao paciente que se submete a transplante, é preciso dizer algo sobre a que corpo se reporta este homem que adoeceu. Sim, pois existem algumas concepções teóricas que o diferenciam conforme a referência conceitual abordada e sua contextualização histórica (Junqueira Filho, 1995).

Segundo a tradição, o homem foi envolvido com dois legados: o platônico e o aristotélico. Na primeira influência interpretativa, a alma é compreendida como o piloto no navio; isto é, subentendem-se duas entidades e diferenças hierárquicas. Na segunda definição, o corpo é visto como órganon, ou seja, não passa de um instrumento da alma, a qual age e relaciona-se no mundo através do corpo. Na verdade, Aristóteles indica uma "mistura" entre alma e corpo, embora também dualista, é diferente de Platão para quem alma e corpo são entidades separadas.

O pensamento platônico assim como o aristotélico conduzem à idéia de que a alma tem potencialmente funções específicas e autônomas, mas que depende das oportunidades corpóreas para realizar suas faculdades.

Descartes, no século XVII, toma posse do conhecimento desses legados e impõe um dualismo rígido entre corpo e alma, cabendo à glândula pineal a função de dar viabilidade ao elo de comunicação entre o corpo e a alma (Junqueira Filho, 1995).

Espinosa afirma que corpo e alma são isonômicos; ou seja, apresentam estados governados pelas mesmas leis. Conseqüentemente extingue a tradição hierárquica entre alma e corpo. Desta forma, o discurso deixa de afirmar que temos uma faculdade intelectual e passa a ser assumido na sua integridade; isto é, somos um intelecto. "Não temos uma faculdade de imaginar, somos imaginantes porque somos pensantes". Assim, pelo pensamento podemos afirmar, negar as idéias e também as imagens. A escolha do posicionamento favorável, ou não, em relação às idéias ou às imagens depende da interferência do desejo. Espinosa diz que "somos desejantes porque somos pensantes". Assim, a alma pode ser compreendida como uma atividade pensante que se manifesta como imaginação, desejo e reflexão (Junqueira Filho, 1995).

Nesta avaliação, o objeto deste pensante é o corpo enquanto a alma é a idéia do corpo. $\mathrm{Na}$ interligação do objeto da idéia configura-se que a alma é um corpo; subentende-se que tudo que aconteça ao corpo é percebido pela alma. Assim, a alma humana está naturalmente vinculada ao corpo e através desta conexão relacional está em condições de perceber as afeções do corpo e as idéias dessas ocorrências e dos inúmeros contextos intrínsecos que envolvem o corpo.

Reportando-se à antigüidade, verifica-se que na doença o médico investia no doente, visando à purificação do corpo e da alma. Assim, diante do adoecimento, a crença era depositada no "médico-divino" e não no médico que fosse apenas humano.

$\mathrm{Na}$ história da medicina, a mitologia grega destaca a presença de Asclépio que se fixou em Epidauro, o qual foi transformado em um famoso centro cultural e espiritual. Naquele contexto ele teria desenvolvido "uma verdadeira escola de medicina, cujos métodos, de início, 
eram sobretudo mágicos, mas que o desenvolvimento preparou o caminho para uma medicina bem mais científica nas mãos dos chamados Asclepíades ou descendentes de Asclépio, cuja figura máxima foi o grande Hipócrates" (Souza, 1996). Na medicina do Asclépio, o que permeava a sua conduta era a ênfase da "nooterapia", isto é, da cura pela mente. Assim, em primeiro lugar buscava a cura da mente e, para esta ocorrer, era fundamental a "metanóia"; ou seja, a transformação dos sentimentos. Investia-se no ser integralmente e não apenas nos sintomas aparentes do adoecimento (Souza, op. cit.).

No século II, o médico grego Cláudio Galeno, na tentativa de compreender a relação dos fatores emocionais e dos componentes de estresse na doença, constatou que as mulheres com câncer de mama tinham temperamento melancólico. Porém, apenas em meados do século XX, a relação mente e saúde tomou um espaço mais significativo no campo da pesquisa (Palmeira, 1997).

Em 1936, o cientista e médico austríaco Hans Seyle apresentou pela primeira vez, em biologia, o conceito de estresse. Conceituou-o como uma síndrome geral de adaptação; ou seja, um conjunto de reações sistêmicas e não específicas que surgem quando ocorre uma exposição do organismo a agentes agressores (Bonamin, 1995; Palmeira, 1997).

\section{Atualmente, cada vez mais se comprova a \\ interligação dos vários sistemas orgânicos, a estrutura psíquica e o contexto do meio ambiente.}

Os conhecimentos conquistados pela medicina e tecnologia conferem às pesquisas um requintado instrumental que possibilita constatações acerca da influência do estresse no sistema simpático medular adrenal, o qual libera cortisol nas situações de desgaste, confirmando que o eixo adreno-cortical hipotalâmico-pituitário secreta catecolamina nas circunstâncias de tensão. Assim, anormalidades estruturais e alterações metabólicas e bioquímicas podem ser observadas durante $o$ adoecimento.

De fato, o avanço tecnológico abre um campo enorme para compreender os diferentes mecanismos que estão imbricados nas doenças e nas interfaces psíquicas e físicas do adoecimento. Com isto, os biologistas moleculares detectam mecanismos psicológicos que influenciam nos transtornos repetitivos, como, por exemplo, o herpes (Melamed, 1995).

A psiconeuroimunologia traz, por meio de enfoques científicos, novos conhecimentos que divulgam a inexistência de personalidades predispostas às doenças auto-imunes, mas, personalidades com potenciais imunossupressores variáveis. Por isso, diante de fatores virais e psicossomáticos, estes podem ou não precipitar ou agir como coadjuvantes na etiopatogenia multifatorial neoplásica. A conexão entre as diversas funções dos sistemas nervoso e imune se aloja na psiconeuroimunologia; ou seja, situa-se neste novo ramo da ciência biológica que tem a sua base centralizada no estudo da fisiologia destes sistemas (Almeida, Loureiro \& Voltarelli, 1998).

Existem inúmeros achados que comprovam a correlação do sistema nervoso central (SNC) e o sistema imune (SI). Almeida et al. (1998) mencionam que: "a serotonina estimula a proliferação dos linfócitos $T$ (células de defesa do sistema imune) e aumenta a síntese de anticorpos", sendo que, pacientes com depressão maior ou outros transtornos distímicos apresentam nível alterado de neuroquímicos como a serotonina e a dopamina. Antes e depois do transplante, o paciente experimenta situações de estresse intenso, com toxidade orgânica, devido a medicamentos e alterações metabólicas que podem interferir no SNC. Associam-se a estas variáveis a incidência de depressão significativa e a ansiedade elevada. É preciso lembrar ainda que são portadores de uma doença hematopoética, e isto significa que os linfócitos T estão diretamente envolvidos. Algumas experiências que tinham o intuito de verificar a ligação anatomofuncional entre o sistema imune e o nervoso confirmaram que, ao lesionar o hipotálamo de ratos, ocorria uma coletânea de alterações nos constructos dos órgãos do sistema linfático, sendo que este local encampa as células do sistema imune (exemplificando: o baço). Conseqüentemente, há uma interferência nas células $T$ e na manutenção dos linfócitos, fator este fundamental nos pacientes do STMO, demonstrando uma das interligações da psique- 
corpo (Bonamin, 1995; Melamed, 1995); Spiegel, 1996; Deitos \& Gaspary, 1997; Palmeira, 1997; Neitzert et al.,1998).

A doença do enxerto contra o hospedeiro (DECH) é causada pela ação dos linfócitos $T$ do doador (imunologicamente competentes) que reconhecem os aloantígenos do receptor como estranhos e causam um dano celular direto ou por intermédio dos mediadores inflamatórios. As células $T$ do doador (ou outras células) também são capazes de reconhecer as células tumorais do paciente e de promover uma reação do enxerto contra a leucemia. Geralmente, os pacientes com doenças malignas, que apresentam uma $\mathrm{DECH}$ grau I ou II, têm menor risco de recaída hematológica após o transplante.

Em outras seqüências de estudos, a conexão do biopsíquico também é endossada na constatação de que, ao ser lesionado, o sistema límbico - relacionado às emoções - apresenta um aumento de células do timo: órgão linfóide primário, responsável pela maturação dos linfócitos T (Bonamin, 1995).

Algumas pesquisas mostram que "a glândula pineal, no SNC, é responsável pela secreção do hormônio melatonina, o qual regula a secreção de outros hormônios, como os da reprodução e o próprio glicocorticóide. Quando essa glândula é retirada, a síntese de anticorpos e a atividade linfocitária diminuem, provavelmente pela alteração desse hormônio" (Bonamin, 1995). Esta citação é apenas uma entre muitas que denotam a importância da interação do SNC e o S Imune; isto é, da neuroimunomodulação que propicia uma direção para a saúde/doença do corpo como um todo.

Investigações sobre modelos de neuroimunologia e os aspectos biopsicossociais trouxeram o conhecimento de que os programas terapêuticos que conduzem o paciente a um manejo do próprio estresse possibilitam condutas positivas e estas influenciam o sistema imunológico humano e o comportamento; propiciando uma aderência ao programa da "vida".

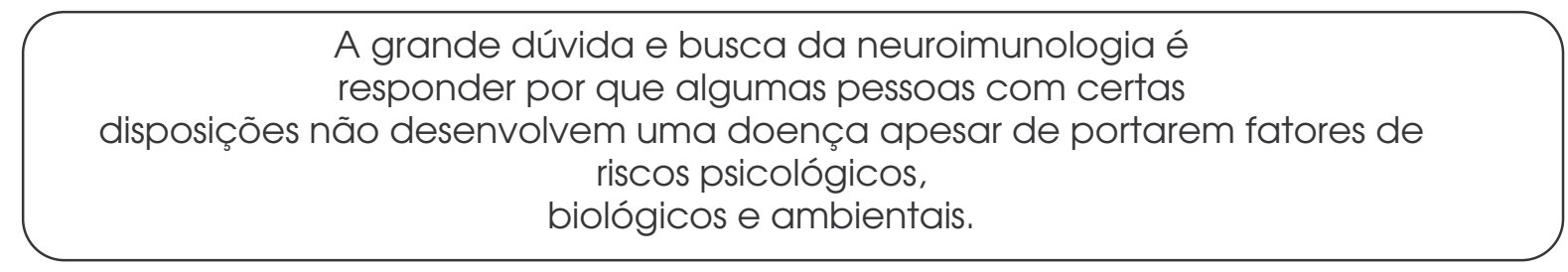

$\mathrm{Na}$ ausência desta resposta, não se obtém um prognóstico definido. Contudo, pode-se continuar a coleta de informações dessa área; pois, assim, o paciente poderá formular as expectativas que condigam com a realidade de uma nova condição de saúde e não a recuperação da saúde que tinha nos períodos que antecederam ao adoecimento. É impossível retornar; é possível reparar (Donnall \& Forman, 1994); Deitos \& Gaspary, 1997).

Devos \& Fontaine (1998) mostram que as expectativas irrealistas a respeito das conseqüências a longo prazo de uma afeção médica e de seus tratamentos influenciam a qualidade de vida do paciente e, mais particularmente, daquele que foi submetido a um enxerto de medula óssea. Parece que a discordância entre as expectativas do sujeito e seu estado funcional atual esteja associada a uma angústia emocional mais importante, cuja qualidade de vida é afetada. Uma intervenção psicoterapêutica pode ser interessante por ajustar as expectativas do paciente a seu estado funcional objetivo. Uma das hipóteses é que a adequação entre as expectativas do paciente quanto às conseqüências a longo prazo do enxerto de medula óssea contribua positivamente na conquista de qualidade de vida.

Schrijvers, Coebergh \& Mackenbach (1997) estudaram a correlação entre qualidade de vida e o nível socioeconômico (NSE) dos pacientes transplantados. Verificaram os seguintes achados: a qualidade de vida e o número de sobreviventes com condições socioeconômicas satisfatórias é maior do que com o nível oposto, pois o tempo que se leva para ter ou confirmar o diagnóstico nos pacientes com recurso econômico precário pode ser longo, o que tem influência 
negativa no sobrevivente, uma vez que pode dar oportunidade à comorbidade. Por conseqüência, quando correlaciona-se o NSE baixo às morbidades, confere-se um aumento de componentes negativos no resultado.

Em seu estudo sobre o ajustamento psicossocial e da qualidade de vida de pacientes submetidos ao transplante, Bonamin (1995) apresenta, entre outros dados, a verificação de que o referencial de QV dos pacientes, para uma maioria, estava centralizado na percepção de livrarem-se dos sintomas oriundos da doença de origem, tendo como foco principal os aspectos físicos e não emocionais, tais como insegurança ou incapacidade, questão diretamente relacionada à necessidade premente de produção, uma vez que pertenciam a um grupo de baixa renda. Após um ano, quando os aspectos vitais foram superados, as dificuldades passaram a um outro âmbito; isto é, à sexualidade e ao relacionamento social, que tomaram um vulto significativo.

Neitzert et al. (1998) demonstraram que indivíduos em processo de recuperação, por vezes, apresentam várias dificuldades psicossociais que thes causam impacto negativo como por exemplo a fadiga, que pode perdurar vários anos após o transplante. Além disso, ocorrem registros de alteração de humor, nível de ansiedade elevado ou comportamentos depressivos, sintomas psiquiátricos e angústia. Também não é incomum o aparecimento ou a exacerbação da dificuldade sexual por vários meses seguidos. Para tal, tem-se iniciado a análise da terapia de reposição hormonal (HRT), achado clínico que está em sintonia com os detectados nas interligações biopsíquicas da neuropsicoimunologia.

Glaus, Crow \& Hammaond (1996) constataram que o sintoma da fadiga é freqüente nas pesquisas de CA e seus tratamentos. Por isto tentaram unificar o conceito de fadiga; pois, por vezes, a fraqueza, a sensação subjetiva de ter dificuldade e certa astenia para iniciar uma determinada atividade são comentários espontâneos que ocorrem por parte dos pacientes quando indagados sobre seu estado de disposição. Tais declarações subjetivas também são interpretadas por alguns investigadores como fadiga. Ainda, ocorre uma associação da fadiga com a queixa do decréscimo da performance física. Assim, a redução na execução física pode limitar a capacidade de superação do cansaço.

Em grupos normais, o cansaço existente é aquele que, após uma boa noite de sono, ou após exercícios físicos e relaxamento, deixa de se fazer presente. Enquanto que nos pacientes com CA, o cansaço é incomum e permanece mesmo com períodos de repouso.

O grupo de pessoas saudáveis ao expressar cansaço pode perceber a sua origem, nas suas diferentes vertentes: afetivas, cognitivas ou físicas. O cansaço está localizado em partes determinadas do corpo, que foram anteriormente envolvidas no trabalho. Para os pacientes com câncer, a percepção fixa-se como uma fadiga crônica, um desprazer, uma limitação física para as atividades da vida. Para estes, o cansaço é uma sensação global, que envolve todo o corpo.

Spiegel (1996) comprovou que o cuidado com os aspectos que podem alterar o humor e a diluição da depressão são atitudes terapêuticas que conferem um melhor ajuste do paciente, uma redução sintomatológica ou, em outras circunstâncias, podem ter uma interferência maior ou menor no curso da doença. Para Spiegel (op. cit.), porém, "aparentemente a capacidade de ficar doente é parte integrante do plano básico da natureza humana apesar dos esforços mentais em contrário".

Nesse sentido, inúmeras pesquisas apontam resultados diversificados, devido a variáveis divergentes, a referenciais diferentes, a condições gerais de vida e a percalços do nível socioeconômico nas quais estão inclusos. Por isso, deve-se levar em consideração todas as possibilidades numa triagem de informações e, na seqüência, deve-se discernir os recursos existentes de modo a adequá-los aos caracteres da amostra que se tem a pretensão de pesquisar, para então poder avaliar o acontecimento da interação do "corpo pensante" que vivencia o transplante de medula óssea.

\section{CONCLUSÃO}

Se neste final de milênio, diante da pesquisa oncológica, deparamo-nos com dificuldades tão elementares como a falta de elaboração de projetos que sejam passíveis de praticidade e 
encontramos uma infra-estrutura especializada incompleta ou até mesmo inexistente, então é factível que as divulgações dos registros protocolares desenvolvidos e dos resultados científicos encontrados no Brasil estejam aquém da demanda, quando se trata de qualidade de vida na recuperação prolongada daqueles que realizam um TMO.

É essencial que se desenvolvam planejamentos, programas de QV e de aprendizagem sobre a melhor forma de manejar as situações de perdas. Para

isso, é preciso descrever e definir o referencial de QV da pessoa que foi acometida por uma doença ainda associada à idéia da morte.

Os receptores de medula óssea, após curto ou longo prazo de sobrevivência, manifestam queixas significativas que denotam uma nova condição de vida que nem sempre corresponde à expectativa inicial. É preciso compreender, para propor no atendimento preventivo, um panorama que seja mais próximo da realidade que os espera e também para amenizar os malefícios decorrentes dos recursos psíquicos inerentes das pessoas que adoeceram, em sua particularidade. Por conseqüência, médicos e psicólogos devem trabalhar juntos, uma vez que o objetivo é o mesmo: possibilitar o bem-estar global do paciente.

A literatura afirma, e a prática confirma; a ciência explica, e a prática replica; estes movimentos complementares são fundamentais para uma compreensão integral, considerando que a relação entre saúde e doença, corpo e psique, é necessária para o processo evolutivo da vida.

É possível concluir que a interação entre o sistema nervoso e o sistema imune sempre acontece. Porém, a forma e a intensidade depositadas na ação e reação do indivíduo contextualizado dependerão da capacidade adaptativa dos vários sistemas orgânicos, da estrutura psíquica e do meio ambiente.

A especificação das queixas mais freqüentes, das perdas que trazem maior dificuldade na readaptação e reabilitação do indivíduo abre um novo caminho para intervenções clínicas mais consistentes, as quais beneficiarão pacientes, familiares, profissionais e ampliarão as chances de este paciente inserir-se com autonomia no meio em que vive.

Enfim, a polaridade do bom e ruim depende também do que é interpretado como verdadeiro. Além disso, sabe-se que tanto o bem-estar como as crises, os confrontos com os complexos psicológicos, as dificuldades com o adoecimento e os problemas arquetípicos ajudam no processo da construção da personalidade; ou seja, aquele que adoece e aquele que cuida do doente podem aproveitar esse processo de enfermidade para construir e contribuir na evolução do próprio homem.

\section{REFERÊNCIAS BIBLIOGRÁFICAS}

Almeida, A. C.; Loureiro, S. \& Voltarelli, J. C. (1998). O Ajustamento psicossocial e a qualidade de vida de pacientes submetidos ao transplante de medula óssea. Medicina, 31, 296-304.

Bonamin, L. V. (1995). O estresse e as doenças. Ciência Hoje, 99(17), 25-30.

Deitos, T. F. H. \& Gaspary, J. F. P. (1997). Efeitos biopsicossociais e psiconeuroimunológicos do câncer sobre o paciente e familiares. Ver. Bras. Cancerol, 43 (2), 117-125.

Donnall, T.; Forman, S. J. \& Blume, K. G. (1994). Bone Marrow Transplantation. Cambridge, Massachusetts: Blackwell Scientific Publications.

Fleck, M.P.A. (1998). Organização mundial de saúde, divisão de Saúde Mental, Grupo WHOQOL. Versão em português dos instrumentos de avaliação de qualidade de vida (WHOQOL) 1998. Obtido em 20 de maio de 1999 do World Wide Web: http://www.hcpa.ufrgs.br/ psig/whogol1.html.

Glaus, A.; Crow, R. \& Hammaond, S. (1996). A qualitative study to explore the concept of fatigue/tiredness in cancer patients and in healthy individuals. Support Care Cancer, 4, 82-96.

Junqueira Filho, L. C. U. (Organizador). (1995). Corpo mente: Uma fronteira móvel. São Paulo: Casa do Psicólogo.

Keogh, F.; Riordan, J. O.; Namara, C. Mc.; Duggan, C. \& McCann, S. R. (1998). Psychosocial adaptation of patients and families following bone marrow transplantation: A prospective, longitudinal study. Bone Marrow Transplantation, 22, 905-911.

Kuss, R. \& Bourget, P. (1992). An illustrated history of organ transplantation. Los Angeles: Publications Laboratory Sandoz. 
McQuellon, R. P.; Russel, G. B.; Rambo, T. D.; Craven, B. L.; Radford, J.; Perry, J. J.; Cruz, J. \& Hurd, D. D. (1998). Quality of life psychological distress of bone marrow transplant recipients: The "time trajectory" to recovery over the first year. Bone Marrow Transplantation, 21, 477-486.

Melamed, B. G. (1995). The interface between physical and mental disorders: The need to dismantle the biopsychosocialneuroimmunological model of disease. Journal of Clinical Psychology in Medical Settings, 3(2), 225-231.

Munstedt, K.; Manthey, N.; Sachsse, S. \& Vahrson, H. (1997). Changes in self- concept and body image during alopecia induced cancer chemotherapy. Support Care Cancer, 5, 139-143.

Neitzert, C. S.; Ritvo, P.; Dancey, J.; Weiser, K.; Murray, C. \& Avery, J. (1998). The psycholosocial impact of bone marrow transplantation: A review of the literature. Bone Marrow Transplantation, 22, 409-422.

Padilla, G. V. (1983). Research in nursing and health, quality of life index for patients with cancer. Journal of pediatric oncology nursing, 6, 117-126.

Palmeira, G. A. (1997). Psique e Câncer. J. Bras. Psiq, 46(3), 157-162.

Rowland, J. H. (1997). Outcomes assessment: Cancer-specific quality-of-life measures-beyond the research setting. American Society of Clinical Oncology, 342-349.

Schrijvers, C. T. M.; Coebergh, J. W. W. \& Mackenbach, J. P. (1997). Socioeconomic Status and Comorbidity among newly diagnosed cancer patients. American Cancer Society, 8(80), 1.482-1.487.

Souza, J. (1996). Mitologia Grega (7ª ed.). Petrópolis: Vozes, v. II.

Spiegel, D. (1996). Cancer and depression. Bristish Journal of Psychiatry, 168(30), 109-116.

Whedon, M. B. \& Wujcik, D. (1997). Blood and Marrow Stem Cell Transplantation. Principles, Practive, and Nursing Insights. ( $2^{\text {nd }}$ ed.). Massachusetts: Jones and Bartlett Publishers. 
